\title{
Evaluation of D-Dimer as a Diagnostic Tool in Patients with Acute Aortic Dissection
}

\author{
Samir Rafla ${ }^{1}\left(\mathbb{B}\right.$, Tarek Bishay $^{2}$ (i) \\ ${ }^{1}$ Cardiology Department, Alexandria University, Alexandria, Egypt \\ ${ }^{2}$ National Heart Institute, Cairo, Egypt \\ Email:smrafla@yahoo.com,Tarek_a_bishay@yahoo.com
}

How to cite this paper: Rafla, $\mathrm{S}$. and $\mathrm{Bi}$ shay, T. (2021) Evaluation of D-Dimer as a Diagnostic Tool in Patients with Acute Aortic Dissection. World Journal of Cardiovas cular Diseases, 11, 135-144. https://doi.org/10.4236/wjcd.2021.112015

Received: December 29, 2020

Accepted: February 21, 2021

Published: February 24, 2021

Copyright (c) 2021 by author(s) and Scientific Research Publishing Inc. This work is licensed under the Creative Commons Attribution International License (CC BY 4.0).

http://creativecommons.org/licenses/by/4.0/ (c) (i) Open Access

\begin{abstract}
Acute (Ac.) Aortic Dissection (AD) is a life threatening cardiovascular emergency. The diagnostic methods (e.g., TEE, MRI, Multislice CT) are limited by availability. A fast, cost effective and technically simple method for diagnosis of AAD is needed. D-Dimer is a measure of clot formation and lysis. The aim of this study was to determine whether assessing D-Dimer level can be used for the diagnosis of AAD. Methods: 45 patients with clinical suspicion of AAD who presented within the first 24 hours from symptom onset were studied prospectively. 20 patients were proved to have AAD by TEE (group I). The other 25 patients had other final diagnosis (group II). All the 20 patients in group I (100\%) with confirmed AAD had positive and elevated D-Dimer levels while only 9 patients in group II (36\%) had positive D-Dimer levels ( $\mathrm{p}$ $<0.001)$. Mean D-Dimer level was significantly higher in the 20 patients in group I than in the 9 patients with positive test in group II $(\mathrm{p}<0.01)$. The sensitivity of D-Dimer was $100 \%$ and the specificity was $64 \%$ for the diagnosis of AAD. Mean D-Dimer level was significantly higher in Stanford type A, AAD than in Stanford type B, AAD, $(\mathrm{p}<0.01) .5$ patients $(25 \%)$ died during the in-hospital course. Mean D-Dimer level was higher in the patients who died. Conclusion: D-Dimer levels are positive and elevated in all the patients with $\mathrm{AAD}$ presenting within the first 24 hours from symptom onset.
\end{abstract}

\section{Keywords}

Aortic Dissection, D-Dimer

\section{Introduction}

$\mathrm{AAD}$ is a life threatening cardiovascular emergency with a mortality rate of $1 \%$ $2 \%$ per hour [1]. AAD, if not diagnosed early is frequently fatal [2]. 
Because the clinical manifestations of $\mathrm{AD}$ are diverse, the clinical presentation may be similar to manifestations of other diseases [3].

Since almost $20 \%$ of patients may present without pain and with non-major symptoms like syncope, cerebrovascular accidents or with congestive heart failure, evaluation of patients with suspicion of AAD is often difficult [1] [4]. It was reported that diagnosis was missed in up to $38 \%$ on initial evaluation [5] [6] [7]. Therefore, the main challenge in managing AAD is to diagnose the disease as early as possible. The choice of initial imaging modality depends on availability not only preference. The newer and preferred diagnostic methods (e.g., TEE, Multislice CT) are still limited by availability. Also, the patients may be hemodynamically unstable for performing these methods [5].

D-Dimers are specific cross-linked fibrin derivatives that are products of the fibrinolytic degradation of fibrin. They are considered the best available laboratory marker of coagulation activation; levels correlate with the extent of thrombosis [2].

A cost effective and technically simple method such as a blood test would be useful in the early diagnostic evaluation of AAD [2].

Aim of the work

To determine whether assessing D-Dimer level can be used for the diagnosis of AAD.

\section{Patients and Methods}

45 consecutive patients with clinical suspicion of AAD who presented within the first 24 hours from symptom onset were studied prospectively at the National Heart Institute during the period between September 2007 and April 2009.

Exclusion criteria:

1) Patients with Intramural Hematoma (IMH) (because other reports [8] stated it can slightly lower the specificity of D-Dimer for AAD). Cases with abdominal aortic dissection were not included.

2) Patients with disseminated intravascular coagulation (DIC).

3) Patients with cerebral or peripheral arterial thromboembolism.

4) Patients with recent trauma or surgery (of less than one month).

5) Patients with malignancies.

6) Patients with liver cirrhosis. 7) Pregnancy.

8) Patients with renal failure.

Every patient was subjected to:

1) Complete history taking.

2) Clinical examination.

3) ECG.

4) Chest X-Ray.

5) Transthoracic Echocardiography (TTE).

6) TEE:

- Was done using multiplane probe. 
- The diagnosis of AAD was done using the standard criteria [9].

- $\mathrm{AD}$ was classified as Stanford type A and Stanford type B: Stanford A: any dissection involving the ascending aorta. Stanford B: any dissection not involving the ascending aorta.

7) Blood sampling procedures:

- Blood samples were drawn on presentation (within 24 hours of symptom onset).

- Measurements and Analysis D-Dimer levels were measured with the commercially available Latex Agglutination test. As analytical methods of diagnostic performance, sensitivity, specificity, calculations were done with Analyze-It software (version 2.03, Leeds, UK). D-Dimer levels for confirmed cases of $\mathrm{AD}$ were compared with those of patient cohorts with other final diagnoses according to type of dissection and time course from symptom onset.

- D-Dimer level was considered negative if a level of $<0.5 \mathrm{ug} / \mathrm{ml}$ was detected and positive if a level of $\geq 0.5 \mathrm{ug} / \mathrm{ml}$ was detected.

- Informed consent was obtained from the patients. Statistical Analysis:

- Quantitative data were expressed as mean \pm standard deviation.

- Student's $t$ test was used to compare quantitative data between 2 groups.

- Discrete variables were compared with chi squared test.

- A value of $\mathrm{p}<0.05$ was considered statistically significant. $\mathrm{p}<0.01$ was considered highly significant.

\section{Results}

45 patients with clinical suspicion of AAD who presented within the first 24 hours from symptom onset were studied prospectively.

20 patients were proved to have AAD by TEE. The other 25 patients had other final diagnosis.

The 20 patients with confirmed AAD constituted group I (AAD group). Of them, 12 patients (60\%) were classified as Stanford type A and 8 patients (40\%) were classified as Stanford type B.

The 25 patients in whom AAD had been ruled out (patients without AAD) constituted group II (control group). Of them, 14 patients (56\%) had acute myocardial infarction (Ac. MI), 6 patients (24\%) had deep venous thrombosis (DVT) and pulmonary embolism (PE), 3 patients (12\%) had unstable angina, and 2 patients $(8 \%)$ had thoracic aortic aneurysm.

1) The baseline clinical characteristics:

Group I: (AAD group):

- Their age ranged from 50.0 to 70.0 years old with a mean of $60.0 \pm 8.20$ years. 12 patients $(60 \%)$ were females $(\mathrm{F})$ and 8 patients $(40 \%)$ were males. 16 patients $(80 \%)$ were in sinus rhythm (SR) and 4 patients (20\%) were in AF. 8 patients (40\%) were diabetics (DM). 13 patients (65\%) had dyslipidemia. 12 patients $(60 \%)$ were smokers. 14 patients $(70 \%)$ were hypertensives $(\mathrm{HTN})$ at 
presentation. LV ejection fraction (LVEE) ranged from $52.0 \%$ to $72.0 \%$ with a mean of $62.0 \% \pm 8.10 \%$.

Group II: (Control group):

- Their age ranged from 48.0 to 68.0 years old with a mean of $58.0 \pm 8.10$ years. 14 patients $(56 \%)$ were females $(\mathrm{F})$ and 11 patients $(44 \%)$ were males. 19 patients (76\%) were in SR and 6 patients (24\%) were in AF. 11 patients (44\%) were diabetics. 17 patients (68\%) had dyslipidemia. 16 patients $(64 \%)$ were hypertensives at presentation. LV EF ranged from $50.0 \%$ to $70.0 \%$ with a mean of $60.0 \% \pm 8.20 \%$.

- Several variables were compared in both groups. The variables analyzed were: age, gender, rhythm, DM, dyslipidemia, smoking and hypertension at presentation.

No statistically significant difference was found between the 2 groups as regards the baseline clinical characteristics (Table 1).

2) D-Dimer:

Group I:

- All the 20 patients in group I with confirmed AAD had positive D-Dimer levels $(100 \%)$.

- D-Dimer levels were elevated in all the patients with a mean of $3.45 \pm 2.96$ $\mathrm{ug} / \mathrm{ml}$.

Group II:

- Only 9 patients in group II without AAD had positive D-Dimer levels (36\%).

- D-Dimer levels were elevated in these 9 patients with a mean of $0.89 \pm 0.65$ $\mathrm{ug} / \mathrm{ml}$. The other 16 patients had negative D-Dimer levels.

a) Comparison between the 2 groups as regards D-Dimer levels:

D-Dimer levels were positive and elevated in all the patients in group I (100\%) versus 9 patients (36\%) in group II, $\mathrm{p}<0.001$ (Figure 1).

Mean D-Dimer level was significantly higher in the 20 patients with positive test in group I than in the 9 patients with positive test in group II $(\mathrm{p}<0.01)$ (Figure 2).

b) The diagnostic value of D-Dimer in AAD:

- All the 20 patients with AAD had positive and elevated D-Dimer levels.

Table 1. Baseline clinical characteristics in both groups.

\begin{tabular}{cccc}
\hline & $\begin{array}{c}\text { Group I AAD } \\
(\mathbf{2 0})\end{array}$ & $\begin{array}{c}\text { Group II Control } \\
(\mathbf{2 5 )}\end{array}$ & P value \\
\hline Age & $60.0 \pm 8.20$ & $58.0 \pm 8.10$ & NS \\
Gender (F) & $12(60 \%)$ & $14(56 \%)$ & NS \\
Rhythm (AF) & $4(20 \%)$ & $6(24 \%)$ & NS \\
DM & $8(40 \%)$ & $11(44 \%)$ & NS \\
Dyslipidemia & $13(65 \%)$ & $17(68 \%)$ & NS \\
HTN at presentation & $14(70 \%)$ & $16(64 \%)$ & NS \\
LVEF & $62.0 \% \pm 8.10 \%$ & $60.0 \% \pm 8.20 \%$ & NS \\
\hline
\end{tabular}




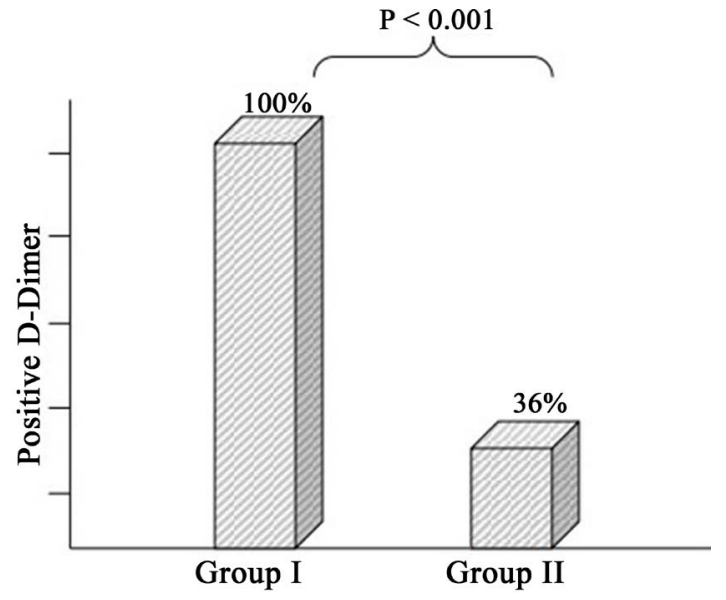

Figure 1. Comparison between the 2 groups as regards D-Dimer.

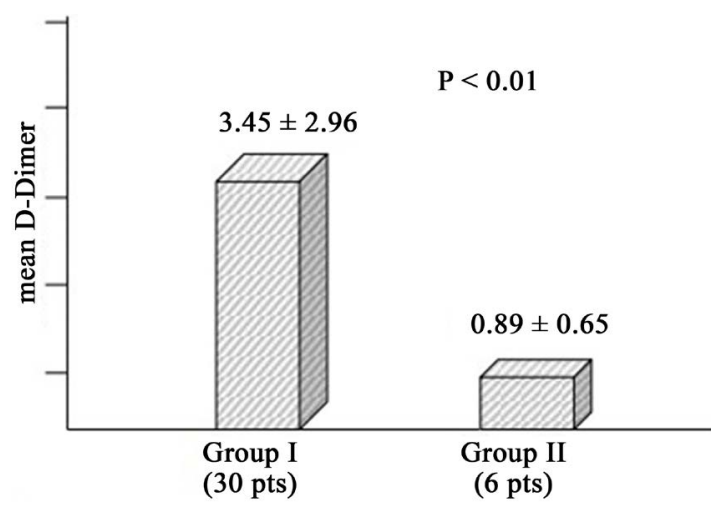

Figure 2. Mean D-Dimer level in both groups.

- 9 of the 25 patients without AAD had positive and elevated D-Dimer levels.

- So, the sensitivity of D-Dimer for the diagnosis of AAD was $100 \%$.

- The specificity of D-Dimer for the diagnosis of AAD was $64 \%$.

c) The type of AAD:

- 12 patients $(60 \%)$ in group I had Stanford A while 8 patients (40\%) had Stanford B.

Mean D-Dimer level was significantly higher in Stanford A (4.92 \pm 2.87 $\mathrm{ug} / \mathrm{ml}$ ) than in Stanford B $(1.25 \pm 1.22 \mathrm{ug} / \mathrm{ml}), \mathrm{p}<0.01$ (Figure 3).

d) The time course from symptom onset of AAD:

- 8 patients (40\%) presented within the first 12 hours from symptom onset.

- 12 patients (60\%) presented from 12 to 24 hours from symptom onset.

Mean D-Dimer level was significantly higher in AAD patients presented within the first 12 hours $(5.75 \pm 2.49 \mathrm{ug} / \mathrm{ml})$ than in patients presented from 12 to 24 hours from symptom onset $(1.92 \pm 2.17 \mathrm{ug} / \mathrm{ml}), \mathrm{p}<0.01$ (Figure 4 ).

e) In-Hospital Mortality:

- 5 patients $(25 \%)$ died during the in-hospital course. 4 patients $(80 \%)$ had Stanford A and 1 patient (20\%) had Stanford B.

- The cause of death was hemopericardium with tamponade in 2 patients, aortic rupture in 2 patients and irreversible shock in one patient. 


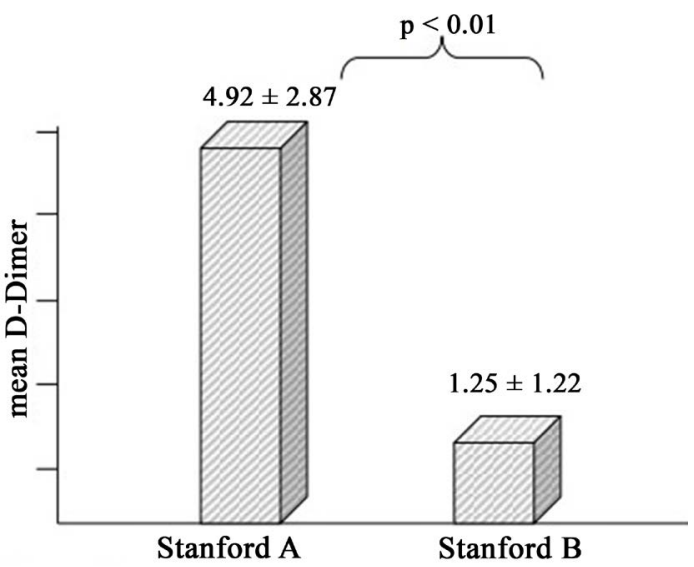

Figure 3. Mean D-Dimer level in Stanford A and Stanford B.

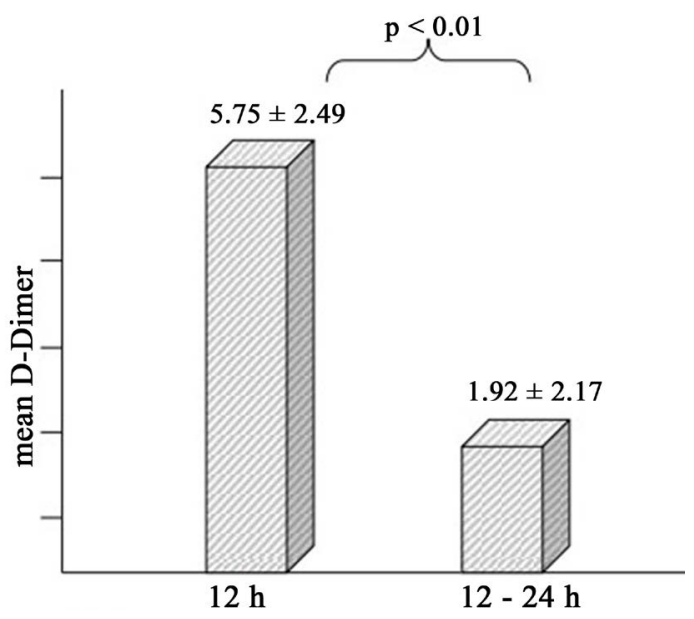

Figure 4. D-Dimer and time course from symptom onset.

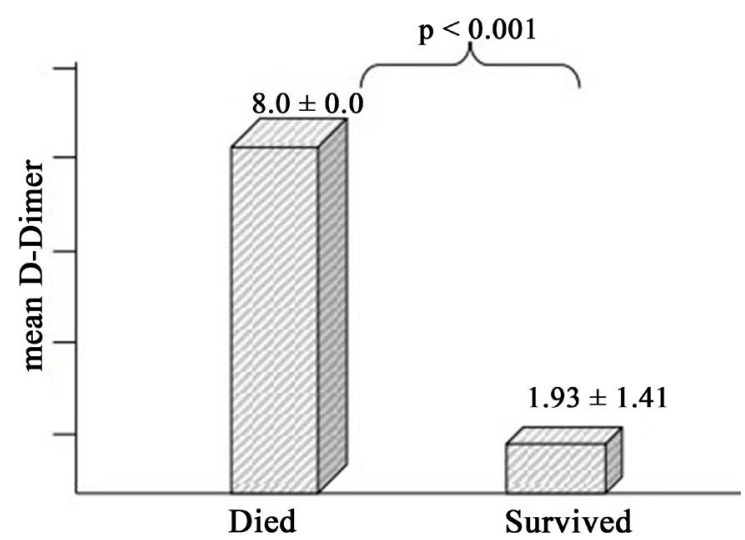

Figure 5. D-Dimer and In-Hospital Mortality.

- 15 patients (75\%) survived. They either underwent successful surgery or medical treatment according to their condition.

- Mean D-Dimer level was significantly higher in the patients who died $(8.0 \pm$ $0.0 \mathrm{ug} / \mathrm{ml})$ than in the patients who survived $(1.93 \pm 1.41 \mathrm{ug} / \mathrm{ml}), \mathrm{p}<0.001$. (Figure 5) 


\section{Discussion}

Acute $\mathrm{AD}$ is a dangerous condition. It can rapidly evolve into a cardiovascular catastrophe misdiagnosed within the initial hours after onset [10]. Clinical suspicion of its presence must be rapidly investigated in the emergency department. Since $\mathrm{AD}$ can occur anywhere within the aorta, the clinical presentation is broad. Therefore, $\mathrm{AD}$ is often difficult to diagnose, and suspicion of its presence must be put in the differential diagnosis [1]. To further improve on the present levels of management of $\mathrm{AAD}$, a cost effective, and fast method for diagnosis of $\mathrm{AAD}$ is needed [3].

D-Dimer results from the destruction of fibrin and therefore is a measure of clot formation and lysis. In turn, the presence of D-Dimer indicates activation of the coagulation systems [11] [12].

In the present study, 20 patients with confirmed AAD constituted group I (AAD group). 25 patients in whom AAD had been ruled out constituted group II (control group). All the 20 patients in group I (100\%) had positive and elevated D-Dimer levels (mean $3.45 \pm 2.96 \mathrm{ug} / \mathrm{ml}$ ). Only 9 patients in group II (36\%) had positive and elevated D-Dimer levels (mean $0.89 \pm 0.65 \mathrm{ug} / \mathrm{ml}$ ). So, D-Dimer levels was positive and elevated in all the patients with AAD (100\%) presenting within the first 24 hours of symptoms onset.

Weber et al. [12], stated that the elevation is D-Dimer levels in AAD is due to activation of the extrinsic pathway of the coagulation cascade at the site of aortic wall injury. Perez et al. [2], suggested that in AAD, the coagulation cascade is elevated by the exposure of thrombogenic material within the arterial wall. Danesh et al. [13], reported that elevated D-Dimer levels are found as a reflection of endogenous fibrinolytic activity, triggered by exposure to tissue factor from the formation of clot in the false lumen or any clot. Thus, D-Dimer levels are specific for fibrinolytic activity triggered by thrombus formation (Table 2).

The result of the present study is in agreement with the results of Weber et al. [12], Suzuki et al. [10] and Perez et al. [2]. Weber et al. [12], reported positive and elevated D-Dimer levels in all the patients with confirmed AAD in their series. Suzuki et al. [10], reported markedly elevated D-Dimer levels in 27 patients with AAD in their series. Perez et al. [2], reported that all seven patients with

Table 2. Comparison of our results with other published reports.

\begin{tabular}{ccccc}
\hline $\begin{array}{c}\text { First Author, year, reference } \\
\text { number }\end{array}$ & $\begin{array}{c}\text { Number of } \\
\text { patients with } \\
\text { AAD }\end{array}$ & $\begin{array}{c}\text { Number of patients } \\
\text { with suspected but } \\
\text { not proved AAD }\end{array}$ & $\begin{array}{c}\text { Sensitivity } \\
\text { (Negative } \\
\text { predictive } \\
\text { value) }\end{array}$ & $\begin{array}{c}\text { Specificity } \\
\text { (Positive } \\
\text { predictive } \\
\text { value) }\end{array}$ \\
\hline Rafla and Bishay (our study) & 20 & 25 & $100 \%$ & $64 \%$ \\
Suzuki et al. (2009) [10] & 24 & 35 & $100 \%$ & $68.6 \%$. \\
Weber et al. (2003) [12] & 14 & 35 & $100 \%$ & $68.6 \%$. \\
Perez et al. (2004) [2] & 7 & 133 & $100 \%$ & Not reported \\
Ohlmann et al. (2006) [14] & 94 & 94 & 99 & 43 \\
\hline
\end{tabular}


AAD in their series had a positive D-Dimer test. Ohlmann et al. [14], reported positive and elevated D-Dimer levels in 93 of 94 patients (99\%) with AAD. Only one patient with AAD had normal D-Dimer level in their series. They reported that D-Dimer levels were significantly lower in patients with intramural hematoma (IMH) than in patients with patent false lumen. However, in the present study, patients with IMH were excluded.

In the present study, D-Dimer levels were positive and elevated in all the patients with AAD (group I) (100\%) versus 9 patients (36\%) in the control group (group II). Similar results were reported by Weber et al. [12], Ohlmann et al. [14] and Suzuki et al. [10]. Weber et al. [12], reported positive and elevation of D-Dimer levels in all the patients with AAD (100\%) compared to 11 patients (31\%) in the control group who had chest pain of other origin. Ohlmann et al. 13 reported mean D-Dimer levels were significantly lower in the control group patients than in AAD patients. Suzuki et al. [10], reported similar results. In the present study, the sensitivity of D-Dimer for the diagnosis of AAD was 100\% and the specificity was $64 \%$. Similarly, Weber et al. [12], reported a sensitivity of $100 \%$ and a specificity of $68.6 \%$.

In the present study, D-Dimer levels were significantly higher in Stanford type A than in Stanford type B. The explanation of this result is that D-Dimer tends to be higher in extended disease. Suzuki et al. [10], suggested that D-Dimer increases proportionally to the surface of contact between the blood stream and the thrombogenic components of the false lumen.

In the present study, D-Dimer levels were significantly higher in AAD patients presented within the first 12 hours than in patients presented from 12 to 24 hours from symptom onset. Weber et al. [12], reported that the time from the beginning of symptoms to D-Dimer testing seems to play a role in determining the absolute $\mathrm{D}$-Dimer value. They suggested that $\mathrm{D}$-Dimer levels caused by tissue injury decrease gradually within the first few days after experiencing the injury. They suggested that the decline is a potential limitation of the diagnostic value of $\mathrm{D}$-Dimer testing in the course of the $\mathrm{AD}$ after the first days, but not in the acute setting. No study is the literature followed the value of D-Dimer levels in the course of $\mathrm{AD}$ after several days. This may be because of the need for urgent handling with the disease.

In the present study, the duration of D-Dimer testing was only within the first 24 hours from symptom onset. In the present study, D-Dimer levels were significantly higher in patients who died than in patients who survived. In accordance with this result, Ohlmann et al. and Watanebe et al. [14] [8] reported the same result.

\section{Conclusions and Recommendations}

1) D-Dimer levels are positive and elevated in all the patients with AAD presenting within the first 24 hours from symptom onset.

2) The sensitivity of D-Dimer for the diagnosis of AAD is $100 \%$. The specific- 
ity of D-Dimer for the diagnosis of AAD is $64 \%$. So, patients with positive and elevated D-Dimer levels should undergo further diagnostic procedures. While a negative $\mathrm{D}$-Dimer test result makes the diagnosis of $\mathrm{AAD}$ is extremely unlikely.

3) Patients with Stanford type A, AAD have a significantly higher D-Dimer level than patients with Sanford type B, AAD.

4) Patients with $A A D$ presenting within the first 12 hours from symptom onset have a significantly higher D-Dimer level than patients presenting from 12 to 24 hours from symptom onset.

5) Patients who die from AAD have a significantly higher D-Dimer level than patients who survive.

6) It is recommended that testing for D-Dimer should be part of the initial assessment of patients presenting with clinical suspicion of $\mathrm{AAD}$, as it is a rapid and noninvasive test.

\section{Ethics of Investigation}

The study was approved by the ethics committee of the National Heart Institute, Cairo, Egypt.

\section{Consent}

All patients gave written consent for the transesophageal echo and for inclusion in the study. No investigation was done without scientific reason. No money was taken from patients.

\section{Conflicts of Interest}

The authors declare no conflicts of interest regarding the publication of this paper.

\section{References}

[1] Hagan, P.G., Nienaber, C.A., Isselbacher, E.M., et al. (2000) The International Registry of Acute Aortic Dissection (IRAD): New Insights into an Old Disease. JAMA, 283, 897-903. https://doi.org/10.1001/jama.283.7.897

[2] Perez, A., Abbet, P. and Drescher, M.J. (2004) D-Dimers in the Emergency Department Evaluation of Aortic Dissection. Academic Emergency Medicine, 11, 397-400. https://doi.org/10.1111/j.1553-2712.2004.tb01460.x

[3] Suzuki, T., Katoh, H., Watanabe, M., Kurabayoshi, M., et al. (1996) Novel Biochemical Diagnostic Method for Aortic Dissection. Circulation, 93, 1244-1249. https://doi.org/10.1161/01.CIR.93.6.1244

[4] Erbel, R., Alfonso, F., Boileau, C., et al. (2001) Diagnosis and Management of Aortic Dissection: Task Force on Aortic Dissection, European Society of Cardiology. European Heart Journal, 22, 1642-1681. https://doi.org/10.1053/euhj.2001.2782

[5] Spittell, P.C., Spittell, J.A., Joyce, J.W., et al. (1993) Clinical Features and Differential Diagnosis of Aortic Dissection: Experience with 236 Cases. Mayo Clinic Proceedings, 68, 642-651. https://doi.org/10.1016/S0025-6196(12)60599-0

[6] Von Kodolitsch, Y., Schwartz, A.G. and Nienaber, C.A. (2000) Clinical Prediction of 
Acute Aortic Dissection. Archives of Internal Medicine, 160, 2977-2982. https://doi.org/10.1001/archinte.160.19.2977

[7] Von Kodolitsch, Y., Nienaber, C.A., Dieckmann, C., et al. (2004) Chest Radiography for the Diagnosis of Acute Aortic Syndrome. The American Journal of Medicine, 116, 73-77. https://doi.org/10.1016/j.amjmed.2003.08.030

[8] Watanabe, H., Horita, N., Shibata, Y., Minegishi, S., Ota, E. and Kaneko, T. (2016) Diagnostic Test Accuracy of D-Dimer for Acute Aortic Syndrome: Systematic Review and Meta-Analysis of 22 Studies with 5000 Subjects. Scientific Reports, 6, Article No. 26893. https://doi.org/10.1038/srep26893

[9] Erbel, R., Daniel, W., Visser, C., Engberding, R., Roelandt, J. and Ronnollet, H. (1989) Echocardiography in Diagnosis of Aortic Dissection. The Lancet, 333, 457-461. https://doi.org/10.1016/S0140-6736(89)91364-0

[10] Suzuki, T., Distante, A., Zizza, A., Trimarchi, S., Villani, M., et al. (2009) Diagnosis of Acute Aortic Dissection by D-Dimer. The International Registry of Acute Aortic Dissection Substudy on Biomarkers (IRAD-Bio) Experience. Circulation, 119, 2702-2707. https://doi.org/10.1161/CIRCULATIONAHA.108.833004

[11] Shon, A.F., Thomas, S.J., Alkins, S.A., Fitzpatrick, T.M. and Ling, G.S. (2002) D-Dimer Correlates with Proinflammatory Cytokine Levels and Outcomes in Critically Ill Patients. Chest, 121, 1262-1268. https://doi.org/10.1378/chest.121.4.1262

[12] Weber, T., Hogler, S., Auer, J., Berent, R., Lassnig, E., Kvas, E. and Eber, B. (2003) D-Dimer in Acute Aortic Dissection. Chest, 123, 1375-1378. https://doi.org/10.1378/chest.123.5.1375

[13] Danesh, J., Whincup, P., Walker, M., et al. (2001) Fibrin D-Dimer and Coronary Heart Disease: Prospective Study and Meta Analysis. Circulation, 103, 2323-2327. https://doi.org/10.1161/01.CIR.103.19.2323

[14] Ohlmann, P., Faure, A., Morel, O., Petit, H., Kabbaj, H., Meyer, N., et al. (2006) Diagnostic and Prognostic Value of Circulating D-Dimers in Patients with Acute Aortic Dissection. Critical Care Medicine, 34, 1358-1364. https://doi.org/10.1097/01.CCM.0000216686.72457.EC

\title{
Abbreviations
}

\author{
$\mathrm{AAD}=$ Acute Aortic Dissection
}

